\title{
Low-Dose Dextromethorphan for the Treatment of Fibromyalgia Pain: Results from a Longitudinal, Single-Blind, Placebo-Controlled Pilot Trial
}

This article was published in the following Dove Press journal:

Journal of Pain Research

\author{
Christina Mueller' \\ Timothy J Ness ${ }^{2}$ \\ Jarred W Younger' \\ 'Department of Psychology, University of \\ Alabama at Birmingham, Birmingham, AL, \\ USA; ${ }^{2}$ Department of Anesthesiology and \\ Perioperative Medicine, University of \\ Alabama at Birmingham, Birmingham, \\ AL, USA
}

Objective: Fibromyalgia (FM) is a debilitating chronic pain condition with few treatment options. Central sensitization and neuroinflammation have been forwarded as models of FM pathophysiology, both of which indicate dextromethorphan (DXM) as a potential treatment. DXM is an NMDA-receptor antagonist and microglial modulator with antineuroinflammatory properties at low doses. It is available for clinical use but has not been tested as a treatment for FM at low dosages. This study evaluated the effectiveness of DXM in treating FM-associated symptoms.

Methods: In a single-blind, placebo-controlled trial, 14 women meeting the 2010 American College of Rheumatology criteria for FM received a placebo for five weeks, followed by $20 \mathrm{mg}$ DXM for ten weeks, while providing daily symptom reports on a $0-100$ scale. Pain and physical activity were the primary and secondary outcomes, respectively. Daily symptom ratings during the last four weeks of placebo were contrasted with ratings during the last four weeks of the active treatment using generalized estimating equations (GEE).

Results: DXM was well tolerated, and treatment adherence was high. Baseline pain was reduced by at least $20 \%$ in six participants. Self-reported daily pain and physical activity in the entire cohort were not significantly different between the placebo and DXM conditions, and the primary hypotheses were not supported. Exploratory analyses using the entire placebo and DXM data showed that pain was significantly lower in the DXM condition than in the placebo condition ( $b=-9.933, p=0.013)$.

Discussion: A strong clinical effect of DXM was not observed at the $20 \mathrm{mg} /$ day dosage. Keywords: fibromyalgia, dextromethorphan, clinical trial, neuroinflammation, analgesia

\section{Introduction}

Fibromyalgia (FM) is a chronic pain condition characterized by widespread pain and a combination of associated symptoms, including unrefreshing sleep, excessive fatigue, cognitive abnormalities, and mood disturbances. ${ }^{1,2}$ The pathophysiology of FM is unclear but is suspected to involve central sensitization and the amplification of nociceptive signaling. ${ }^{3-8}$ Abnormal levels of corticotropin-releasing factor, ${ }^{9,10}$ various neurotransmitters, ${ }^{11-14}$ and opioid peptides ${ }^{15}$ have also been found, implicating complex pathophysiological mechanisms in the disease that have not been fully elucidated. In part due to an incomplete understanding of its pathophysiology, there are few effective treatments for FM. Three medications (pregabalin, duloxetine, and milnacipran) have been approved by the Food and Drug Administration (FDA) for pain management in FM, but their efficacy is modest. ${ }^{16-18}$ Opioid
Correspondence: Jarred W Younger Department of Psychology, University of Alabama at Birmingham, $\mathrm{CH} 233,1300$ University Blvd, Birmingham, AL 35233, USA

Tel +I (205) 975-5907

Fax +l (205) 934-6440

Email younger@uab.edu 
analgesics are not indicated for chronic use in FM, as these medications have been associated with worse long-term outcomes. ${ }^{19-23}$ With many FM patients failing to respond to any available treatments, there is a significant need to test novel treatments for the disorder. Part of that process is identifying the most promising treatment candidates based on our current understanding of FM pathophysiology, and prioritizing compounds that are currently available for clinical use.

While the cause of widespread pain in FM is unknown, research has pointed to abnormal nociceptive/pain processing in the central nervous system. Several hypotheses of FM pathophysiology center on abnormal inflammatory processes in the brain and spinal cord. A recent positron emission tomography (PET) imaging study using the translocator protein (TSPO) radioligand [11C]-PBR28 found that individuals with FM showed increased microglia activation in the brain, compared to healthy controls. ${ }^{24}$ In their activated state, these cells produce proinflammatory cytokines, including tumor necrosis factor$\alpha$ (TNF- $\alpha$ ), interleukin (IL)-18, IL-6, chemokines, and reactive oxygen species. ${ }^{25-29}$ When these proinflammatory factors are chronically present in the brain, they can lead to several symptoms that are central features of FM, including widespread pain and pain sensitivity, ${ }^{30}$ chronic fatigue, and cognitive and mood abnormalities. $^{31-35}$

Few medications with microglia-modulating properties have been formally tested in FM. One exception is the tolllike receptor 4 (TLR-4) antagonist naltrexone, which we have shown previously to ameliorate FM symptoms, ${ }^{36,37}$ and to decrease peripheral concentrations of proinflammatory factors. ${ }^{38}$ While a potentially useful tool in managing FM, many individuals do not respond at all to the treatment, so other microglia-modulating compounds should be explored.

This pilot clinical trial focuses on the oral N-methylD-aspartate (NMDA) receptor antagonist dextromethorphan (DXM). While more commonly known for its dissociative and antitussive effects, DXM has been demonstrated to reduce microglial production of proinflammatory cytokines TNF- $\alpha$, IL- 6 , nitric oxide, and superoxide free radicals. ${ }^{39-43}$ Its active metabolite, 3-hydroxymorphinan, may play a particularly important neuroprotective role, as it inhibits microglia production of proinflammatory factors after exposure to lipopolysaccharide. ${ }^{44}$ DXM is FDA-approved at $20 \mathrm{mg}$ once or twice daily for the treatment of Pseudobulbar
Affect in neurodegenerative and neuroinflammatory conditions. Only one published study has examined the clinical efficacy of DXM in FM. ${ }^{45}$ That study reported positive responses in $35 \%$ of participants after 4-6 weeks of treatment. However, adverse side-effects (eg, nausea and sedation) were reported in over $40 \%$ of participants, likely due to the large dosage used (over $200 \mathrm{mg}$ per day), which is known to produce a variety of unwanted effects. ${ }^{46}$

Because large dosages of DXM can produce significant sedative, dissociative, and hallucinogenic effects, we investigated much lower dosages of the medication. Lower dosages of DXM may be able to reduce neuroinflammation ${ }^{47}$ without blocking NMDA receptors, thus avoiding unwanted dissociative effects. The aim of this pilot study was to determine if DXM should be further investigated as a possible treatment for FM. Fourteen women with FM received placebo for five weeks, followed by DXM for ten weeks while providing daily symptom reports. We hypothesized that generalized pain ratings would be significantly lower during the last four weeks of DXM treatment versus the last four weeks of placebo (primary outcome). We further hypothesized that physical activity during the last four weeks of DXM would be significantly higher than physical activity during the last four weeks of placebo (secondary outcome), reflecting improved functioning. Finally, we conducted exploratory analyses to investigate DXM's effects on maximum pain, muscle pain, fatigue and depressed mood.

\section{Materials and Methods Design}

This clinical trial utilized a longitudinal, single-blind, placebo-controlled design to assess changes in selfreported symptoms as a result of treatment with DXM. Fourteen women with FM completed symptom reports daily at bedtime throughout their study participation. In the two-week baseline phase, participants completed the daily surveys with no intervention. In the placebo phase, participants took one inert capsule in the morning and one in the evening for five weeks. Participants then entered the ten-week DXM phase, and took one $10 \mathrm{mg}$ DXM capsule in the morning, and one at night. Participants were blinded to the administration schedule and placebo capsules looked identical to DXM capsules, but contained only cellulose. Finally, participants 
completed a two-week follow-up period, with continued daily symptom reports.

\section{Participants}

Fourteen women aged 23 to 65 who met FM criteria as outlined by the American College of Rheumatology $(\mathrm{ACR})^{1,2}$ were enrolled in this study. As outlined in the criteria, we utilized a count of painful body parts in the upper left, upper right, lower left, lower right, and axial body regions (Widespread Pain Index, WPI; range: 0-19). The severity of secondary symptoms (Symptom Severity Scale, SSS; range: 0-12) was quantified as the sum of the following self-report ratings: fatigue (range: $0-3$ ), waking unrefreshed (range: 0-3), cognitive complaints (range: $0-3)$, headaches $(0=$ absent; $1=$ present $)$, abdominal pain $(0=$ absent; $1=$ present $)$, and depression $(0=$ absent; $1=$ present). Per the ACR criteria, FM is present if the following are satisfied: 1) a WPI score of at least 7 plus an SSS of at least 5 OR a WPI score of 4-6 plus an SSS of at least 9;2) presence of generalized pain affecting four out of five body regions; and 3) the symptoms have been present for at least three months. Additionally, we calculated an FM Severity index as the sum of the WPI and SSS. Due to the uncertainty that often surrounds FM diagnosis in the early stages, participants must have had FM symptoms for at least 12 months to qualify for this study, and report average daily levels of pain of at least 6 on an 11-point scale (0-10). The following exclusion criteria were applied: pregnancy or lactation, blood draw contraindications (eg, blood clotting disorder), rheumatologic or auto-immune conditions, fever, significant psychological comorbidity, Hospital Anxiety and Depressions Scale (HADS) depression score of $\geq 16$, participation in another treatment trial, illicit substance use, and surgeries or vaccinations in the past 4 weeks. In addition, abnormal values on the following clinical labs were exclusionary: high-sensitivity c-reactive protein $\geq 10 \mathrm{mg} / \mathrm{L}$, erythrocyte sedimentation rate $>60 \mathrm{~mm} / \mathrm{hr}$, positive rheumatoid factor, thyroid-stimulating hormone or free thyroxine outside reference values. Finally, participants could not be taking anticoagulants, monoamine oxidase inhibitors, antibiotics, or daily anti-inflammatory medications (eg, aspirin, ibuprofen, naproxen).

\section{Procedures}

This trial was registered on ClinicalTrials.gov (NCT03538054). The primary outcome was overall body pain ratings during the final four weeks of placebo and DXM. Secondary outcomes were physical activity ratings during the last four weeks of placebo and DXM, and selfreported scores on the Patient Global Impressions of Change scale (PGIC) ${ }^{48}$ All study procedures were carried out under approvals from the University of Alabama at Birmingham (UAB) Institutional Review Board (protocol \#: F161018005). This trial was conducted in accordance with the Declaration of Helsinki.

Participants were recruited from the laboratory's database of individuals who had previously indicated an interest in research studies. Additional participants were recruited via electronic advertisements, flyers, and social media posts. Potential participants made contact with the research team by phone or e-mail and underwent phone screening, which involved the collection of demographic data, medical history, and current symptomatology relating to FM diagnostic criteria and study inclusion criteria. Those meeting initial inclusion criteria were scheduled for an in-person visit at UAB to provide written informed consent, blood samples and vital signs, and to undergo pregnancy testing. At the in-person visit, blood was drawn to conduct exclusionary lab tests. Participants completed the Brief Pain Inventory (BPI), ${ }^{49} \mathrm{HADS},{ }^{50}$ the Stanford Expectations of Treatment Scale (SETS), ${ }^{51}$ and the Drug Abuse Screening Test (DAST-10) ${ }^{52}$ to establish the presence of problematic drug use. Lastly, participants received a handheld tablet and instructions for completing symptom questionnaires at home. Eligible participants returned for five additional visits, each of which involved an assessment of adverse events, measurement of vital signs, blood draws to check renal and hepatic functioning (Visits 3, 4, and 5), and disbursement of medications. The timing of renal and hepatic panels was chosen to correspond with the conclusion of placebo treatment (end of week 7), midway through DXM treatment (week 12), and conclusion of DXM treatment (end of week 17), respectively. Participants were paid $\$ 550$ for completing the study.

\section{Description of Active Treatment}

DXM reaches peak serum levels at 2.5 hours, ${ }^{53}$ and has a half-live of approximately four hours. It is lipid-soluble and readily crosses the blood-brain-barrier. ${ }^{54}$ It is used at dosages of 10-120 mg daily for antitussive treatment due to its antagonist action at NMDA receptors. Previous literature has suggested that DXM at $0.1 \mathrm{mg} / \mathrm{kg}$ intraperitoneally reduces central inflammation. ${ }^{47}$ The dosage used in this study (20mg/day) is similar to the current FDAapproved use for Pseudobulbar Affect. This dosage is below the threshold which would produce diminished 
driving performance $(120 \mathrm{mg}){ }^{55}$ cognitive functioning defects $(400 \mathrm{mg}),{ }^{56}$ or hallucinogenic side effects (400 $\mathrm{mg}){ }^{57}$ DXM was compounded by Double Oak Mountain Pharmacy (Birmingham, AL, United States).

\section{Daily Symptom Reports}

The outcome measures were designed to capture the symptoms most endorsed by FM patients: pain, physical activity, fatigue, and depressed mood. Participants completed a 23-item symptom questionnaire daily at bedtime on a handheld tablet. Pain was rated in response to the prompt, "How would you rate your general level of pain today?", and physical activity was rated in response to, "What was your overall level of activity today?" Other items were worded similarly. The severity of each symptom was rated on a scale ranging from 0 to 100 . The questionnaires were implemented in Qualtrics software (Qualtrics, Provo, UT, United States).

\section{Compliance Checks}

Compliance with the medication regime was established using electronic medication bottle caps (MEMS Cap, Aardex Group Ltd, Seraing, Belgium), which recorded the dates and times each bottle was opened. The target compliance rate was $80 \%$.

\section{Statistical Analyses}

Statistical analyses were performed in SAS software, Version 9.4 of the SAS System for Windows (SAS Institute Inc., Cary, NC, United States). The primary outcome was the difference in daily self-reported general pain during the last four weeks of placebo versus the last four weeks of DXM treatment. Normality testing was performed with Shapiro-Wilk tests. Participant outcome scores were mean-centered by participant, allowing analyses to reflect within-person changes to the treatments, rather than between-person differences. A generalized estimating equations (GEE) model is fitted to predict daily symptom severity based on study condition (placebo, DXM), assuming the autoregressive correlation structure and normal distributions. The grouping variable was subject ID. Significance of the parameter estimates was assumed at $p<0.05$.

The secondary outcome (self-reported physical activity) was tested using the same GEE approach. Additionally, exploratory analyses (highest pain, muscle pain, fatigue, and depressed mood) were tested in separate GEEs.

\section{Results}

\section{Participant Demographics}

Figure 1 shows the number of individuals successfully entering each section of the study. Twenty-seven women met the initial screening criteria and attended the screening visit. Eight were excluded due to not meeting criteria (out-of-range values on blood tests: $\mathrm{n}=5$; medication interactions: $\mathrm{n}=1$; scheduled surgery: $\mathrm{n}=1$; illicit substance use: $\mathrm{n}=1$ ), and 19 women were enrolled in the protocol. One person was removed from the study during the baseline period for starting a new medication containing DXM (acetaminophen-DXM-phenylephrine, Theraflu, GlaxoSmithKline, Brentford, United Kingdom), two participants withdrew during the placebo period, one was removed for poor medication adherence, and one was removed for unreliable symptom reporting. Data from 14 women were available for analyses.

Table 1 presents participant demographics, comorbid medical conditions, and concomitant medication use in the final sample. Participants' average age was 47.07 years $(\mathrm{SD}=10.74)$. The mean duration of FM was ten years and two months $(\mathrm{M}=10.19, \mathrm{SD}=6.90)$, and participants reported an average FM severity of $22.14(\mathrm{SD}=3.76)$ out of 31 , based on the ACR criteria. Four participants were on FDA-approved medications for FM (duloxetine: $\mathrm{N}=4$; pregabalin: $\mathrm{N}=0$; milnacipran: $\mathrm{N}=0$ ). Table 2 presents individual scores and group means on the baseline questionnaires. Participants reported a moderate level of pain severity on the BPI at baseline $(\mathrm{M}=5.86, \mathrm{SD}=1.57)$, and a moderate level of pain interference on daily activities $(\mathrm{M}=5.98, \mathrm{SD}=1.68)$. The HADS revealed moderate average anxiety symptoms $(\mathrm{M}=10.57, \mathrm{SD}=4.43)$ and mild-to-moderate depressive symptoms $(\mathrm{M}=8.36, \mathrm{SD}=4.03)$. The SETS revealed moderate positive $(\mathrm{M}=4.14, \mathrm{SD}=0.77)$ and low negative $(\mathrm{M}=1.79, \mathrm{SD}=1.06)$ treatment expectations prior to the start of the intervention.

\section{Treatment Adherence and Protocol Deviations}

Participants spent an average of 33 days in the placebo period (range: $26-48$ days) and 67 days in the DXM period (range: 38-96). Medication adherence was $93.65 \%(\mathrm{SD}=6.65)$ in the placebo condition and $88.81 \%$ (6.80) during the DXM condition. One participant did not meet the adherence goal $(80 \%)$ during the placebo period, and one participant did not meet the goal during placebo, but both achieved over $78 \%$ adherence.

One individual (participant 004) experienced a tablet malfunction that was not detected until protocol completion. Data from the baseline and the first two weeks of 

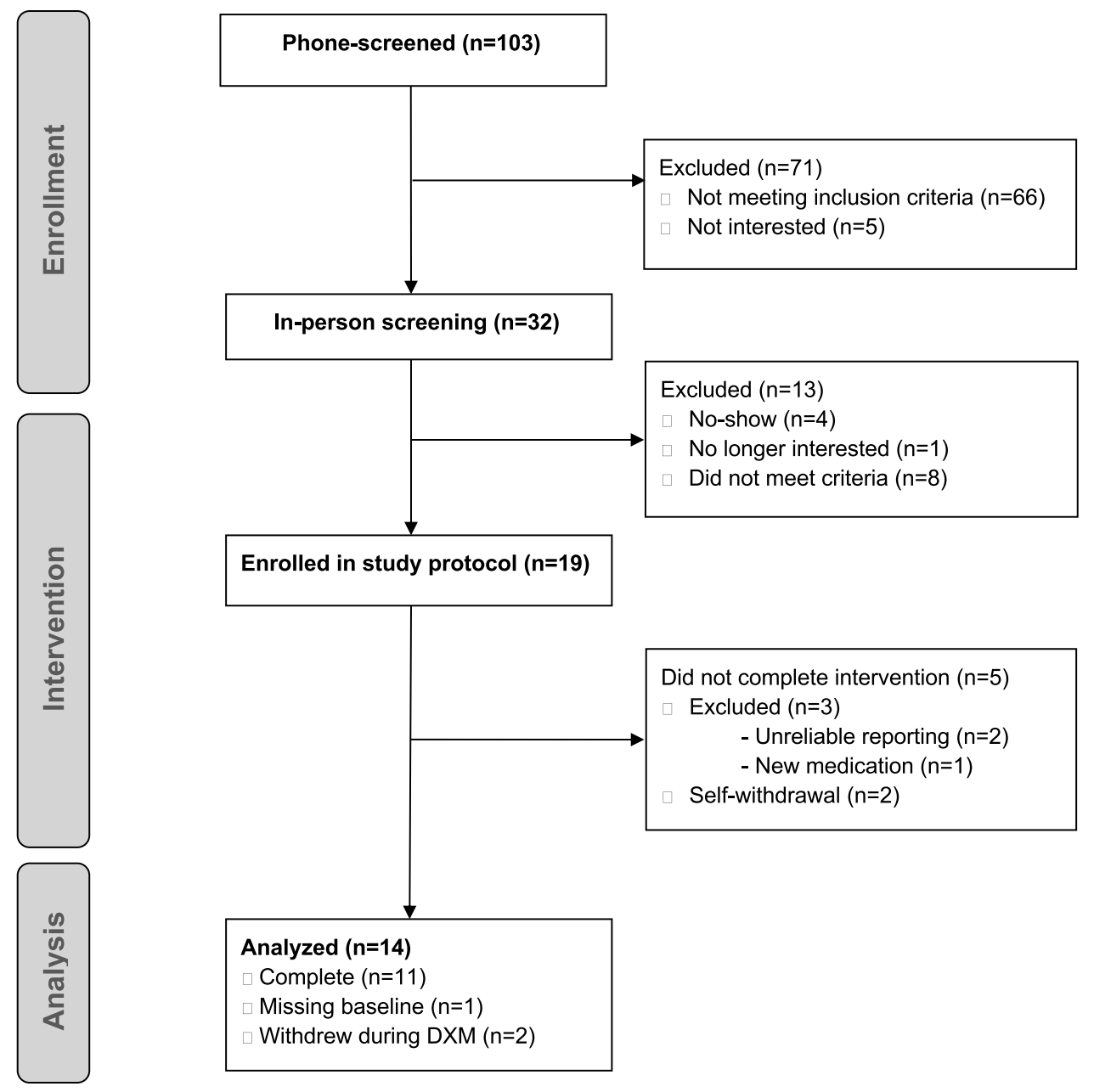

Figure I Participant flow chart.

the placebo condition were lost. This individual was still included in the analyses because she had sufficient placebo and DXM reports. One participant (003) voluntarily withdrew from the study during active treatment due to initiating a new treatment with naltrexone. Another participant (010) withdrew during DXM due to worsened pain, anxiety, and hot flashes. Participant 003 completed seven weeks of the active treatment, and participant 010 completed five weeks of the active treatment, which was deemed sufficient for inclusion in the analyses.

Scores for the PGIC secondary outcome were not available for analyses due to administrator error. The PGIC was inadvertently left out of the lab visit packet for several of the participants.

\section{Blinding Efficacy}

Participants were asked to indicate at each in-person visit whether they believed to have been taking placebo or DXM during the previous five weeks. Participants guessed the correct treatment $57 \%$ of the time, on average. Participants did not guess above chance level during either the placebo period $\left[\mathrm{X}^{2}(1)=2.236, p=\right.$ $0.135]$, the first five weeks of DXM treatment $\left[X^{2}(1)\right.$ $=0.286, p=0.593]$, or the last five weeks of DXM [ $\mathrm{X}^{2}$ $(1)=0.627, p=0.429]$.

\section{Main Treatment Effects}

Table 3 displays group means for the primary outcome of generalized body pain across the four conditions: baseline, placebo, DXM, and end baseline. Individual changes in generalized pain ratings between the placebo and DXM conditions and the mean change for the entire sample are visualized in Figure 2. No significant difference in pain ratings between the placebo (mean pain $=45.5)$ and DXM (mean pain $=41.1)$ conditions were found when contrasting the final four weeks of each condition with the GEE $(b=-5.065, p=0.146)$. 
Table I Individual and Group-Level Illness Characteristics, Comorbid Medical Conditions, and Medications Reported in the Sample

\begin{tabular}{|c|c|c|c|c|c|c|c|}
\hline PID & Age & $\begin{array}{l}\text { FM } \\
\text { Duration } \\
\text { (Years) }\end{array}$ & $\begin{array}{l}\text { WPI } \\
(0-19)\end{array}$ & $\begin{array}{l}\text { SSS } \\
(0-12)\end{array}$ & $\begin{array}{l}\text { FM } \\
\text { Severity } \\
(0-31)\end{array}$ & Comorbid Conditions & Medications \\
\hline 001 & 56 & 12.0 & 11 & 6 & 17 & Osteoarthritis & $\begin{array}{l}\text { Ibuprofen PRN*, acetaminophen PRN*, } \\
\text { naproxen PRN* }\end{array}$ \\
\hline 002 & 23 & 5.0 & 19 & 9 & 28 & None & Phenazopyridine* \\
\hline 003 & 41 & 4.0 & 16 & 9 & 25 & $\begin{array}{l}\text { CFS, hypothyroidism (non-Hashimoto), } \\
\text { sleep apnea, hypercholesterolemia, anxiety, } \\
\text { depression }\end{array}$ & $\begin{array}{l}\text { Acetaminophen PRN*, meloxicam PRN, } \\
\text { sumatriptan PRN*, melatonin*, trazodone* } \\
\text { diphenhydramine PRN*, ranitidine, } \\
\text { famotidine, bismuth subsalicylate PRN*, } \\
\text { cyclobenzaprine PRN*, Armor Thyroid, } \\
\text { atorvastatin, rosuvastatin, amlodipine, } \\
\text { sertraline, lorazepam PRN, iron }\end{array}$ \\
\hline 004 & 48 & 20.0 & 14 & 7 & 21 & $\begin{array}{l}\text { CFS, HTN, GERD, hypercholesterolemia, } \\
\text { interstitial cystitis, depression, anxiety }\end{array}$ & $\begin{array}{l}\text { Ranitidine, dexlansoprazole, fluoxetine, } \\
\text { atorvastatin, amlodipine, carvedilol }\end{array}$ \\
\hline 005 & 46 & 6.2 & 15 & 8 & 23 & Depression, anxiety & $\begin{array}{l}\text { Tizanidine, topiramate, escitalopram, biotin, } \\
\text { Vitamin D, iron, Vitamin BI2 (injections) }\end{array}$ \\
\hline 006 & 48 & 10.0 & 14 & 5 & 19 & Osteoarthritis, tendonitis & $\begin{array}{l}\text { Ibuprofen PRN*, acetaminophen PRN*, } \\
\text { naproxen PRN*, fenofibrate, aspirin, } \\
\text { duloxetine, pseudoephedrine (cold), Vitamin } \\
\text { D, Vitamin BI2, turmeric, magnesium }\end{array}$ \\
\hline 007 & 34 & 19.0 & 12 & 12 & 24 & $\begin{array}{l}\text { CFS, idiopathic hypersomnia, sleep apnea, } \\
\text { chronic migraines, hypothyroidism (non- } \\
\text { Hashimoto), fatty liver disease (non- } \\
\text { alcoholic), OCD, anxiety }\end{array}$ & $\begin{array}{l}\text { Ibuprofen PRN*, acetaminophen PRN*, } \\
\text { clonazepam*, omeprazole, fluoxetine, } \\
\text { levothyroxine, Adderall, doxycycline (sinus } \\
\text { infection), multivitamin, Vitamin D3, turmeric }\end{array}$ \\
\hline 008 & 51 & 4.0 & 16 & 12 & 28 & $\begin{array}{l}\text { Migraines, HTN, IBS, carpal tunnel } \\
\text { syndrome, depression, anxiety }\end{array}$ & $\begin{array}{l}\text { Ibuprofen PRN*, amitriptyline PRN*, } \\
\text { tizanidine PRN*, melatonin PRN*, } \\
\text { diphenhydramine PRN*, losartan, duloxetine, } \\
\text { Vitamin BI2, fish oil, calcium, iron }\end{array}$ \\
\hline 009 & 57 & 15.0 & 16 & 9 & 25 & $\begin{array}{l}\text { Osteoarthritis, sleep apnea, degenerative } \\
\text { disk disease, hypercholesterolemia, pre- } \\
\text { diabetes }\end{array}$ & $\begin{array}{l}\text { Acetaminophen PRN*, naproxen PRN*, } \\
\text { melatonin PRN*, meloxicam, aspirin, } \\
\text { mirabegron, ketorolac injection, ceftriaxone } \\
\text { injection, liraglutide, omeprazole, montelukast, } \\
\text { cetirizine, vortioxetine, fenofibrate, } \\
\text { fluticasone inhaler PRN, sulfamethoxazole/ } \\
\text { trimethoprim (UTI), multivitamin, calcium }\end{array}$ \\
\hline 010 & 61 & 21.2 & 13 & 8 & 21 & Osteoporosis & $\begin{array}{l}\text { Acetaminophen PRN*, meloxicam PRN*, } \\
\text { gabapentin, duloxetine, diphenhydramine } \\
\text { (acute allergic reaction), cortisone topical } \\
\text { (acute allergic reaction), steroid injection } \\
\text { (poison ivy exposure), alendronic acid, CBD oil }\end{array}$ \\
\hline 011 & 39 & 5.0 & 9 & 10 & 19 & CFS, hypothyroidism (non-Hashimoto) & $\begin{array}{l}\text { Acetaminophen PRN*, chlorpheniramine } \\
\text { PRN* }\end{array}$ \\
\hline 012 & 46 & 1.5 & 17 & 7 & 24 & None & Ibuprofen PRN*, Vitamin D \\
\hline 013 & 46 & 3.8 & 11 & 9 & 20 & $\begin{array}{l}\text { CFS, HTN, mitral valve prolapse, acoustic } \\
\text { neuroma, migraines, trigeminal neuralgia, } \\
\text { cervical disk herniation, hypothyroidism } \\
\text { (non-Hashimoto), carpal tunnel syndrome, } \\
\text { anxiety, depression }\end{array}$ & $\begin{array}{l}\text { Diclofenac, duloxetine, gabapentin, Adderall } \\
\text { XR, carbamazepine, lorazepam, } \\
\text { pantoprazole }\end{array}$ \\
\hline
\end{tabular}


Table I (Continued).

\begin{tabular}{|c|c|c|c|c|c|c|c|}
\hline PID & Age & $\begin{array}{l}\text { FM } \\
\text { Duration } \\
\text { (Years) }\end{array}$ & $\begin{array}{l}\text { WPI } \\
(0-19)\end{array}$ & $\begin{array}{l}\text { SSS } \\
(0-12)\end{array}$ & $\begin{array}{l}\text { FM } \\
\text { Severity } \\
(0-3 I)\end{array}$ & Comorbid Conditions & Medications \\
\hline 014 & 63 & 16.0 & 10 & 6 & 16 & $\begin{array}{l}\text { Osteoarthritis, chronic constipation, } \\
\text { insomnia, hypercholesterolemia }\end{array}$ & $\begin{array}{l}\text { Aspirin PRN*, tizanidine PRN*, zolpidem } \\
\text { PRN*, pravastatin, ranitidine, calcium, } \\
\text { magnesium }\end{array}$ \\
\hline $\begin{array}{l}\text { Average } \\
\text { (SD) }\end{array}$ & $\begin{array}{l}47.07 \\
(10.74)\end{array}$ & $\begin{array}{l}10.19 \\
(6.90)\end{array}$ & $\begin{array}{l}13.79 \\
(2.91)\end{array}$ & $\begin{array}{l}8.36 \\
(2.10)\end{array}$ & $\begin{array}{l}22.14 \\
(3.76)\end{array}$ & - & - \\
\hline
\end{tabular}

Note: *Medication use was reported on daily questionnaires during the trial.

Abbreviations: ACR, American College of Rheumatology; CFS, chronic fatigue syndrome; FM, fibromyalgia; GERD, gastroesophageal reflux disease; HTN, hypertension; IBS, irritable bowel syndrome; OCD, obsessive-compulsive disorder; SD, standard deviation; SSS, Symptom Severity Scale; WPI, Widespread Pain Index.

Table 2 Individual and Group-Level Characteristics and Questionnaire Results from the Screening Visit

\begin{tabular}{|c|c|c|c|c|c|c|c|c|}
\hline PID & $\begin{array}{l}\text { BPI Severity } \\
(0-10)\end{array}$ & $\begin{array}{l}\text { BPI Interference } \\
(0-10)\end{array}$ & $\begin{array}{l}\text { HADS-A } \\
(0-21)\end{array}$ & $\begin{array}{l}\text { HADS-D } \\
(0-21)\end{array}$ & $\begin{array}{l}\text { HADS Total } \\
(0-42)\end{array}$ & $\begin{array}{l}\text { DAST-10 } \\
(0-10)\end{array}$ & $\begin{array}{l}\text { SETS Positive } \\
\text { Expectations } \\
(1-7)\end{array}$ & $\begin{array}{l}\text { SETS Negative } \\
\text { Expectations } \\
(1-7)\end{array}$ \\
\hline 001 & 5.25 & 4.33 & 6 & 6 & 12 & 0 & 4.00 & 1.00 \\
\hline 002 & 7.00 & 6.11 & 16 & 4 & 20 & 1 & 4.33 & 2.00 \\
\hline 003 & 3.25 & 6.22 & 10 & 10 & 20 & 0 & 4.00 & 1.67 \\
\hline 004 & 6.75 & 4.44 & 15 & 14 & 29 & 0 & 3.67 & 1.00 \\
\hline 005 & 4.25 & 7.67 & 10 & 10 & 20 & 1 & 4.00 & 4.00 \\
\hline 006 & 3.50 & 2.78 & 10 & 7 & 17 & 0 & 3.67 & 1.00 \\
\hline 007 & 7.00 & 7.78 & 10 & 9 & 19 & 0 & 4.00 & 2.67 \\
\hline 008 & 7.00 & 7.67 & 15 & 14 & 29 & 0 & 6.00 & 2.67 \\
\hline 009 & 4.25 & 6.00 & 10 & 7 & 17 & 0 & 4.00 & 1.00 \\
\hline 010 & 6.25 & 5.22 & 2 & 3 & 5 & 0 & 4.00 & 1.33 \\
\hline 011 & 5.50 & 4.11 & 8 & 6 & 14 & 0 & 5.33 & 1.00 \\
\hline 012 & 7.75 & 8.78 & 14 & 14 & 28 & 0 & 3.00 & 1.00 \\
\hline 013 & 6.00 & 5.89 & 17 & 11 & 28 & 1 & 3.33 & 1.00 \\
\hline 014 & 8.25 & 6.78 & 5 & 2 & 7 & 0 & 4.67 & 3.67 \\
\hline Group Average (SD) & $5.86(1.57)$ & $5.98(1.68)$ & $10.57(4.43)$ & $8.36(4.03)$ & $18.93(7.78)$ & $0.21(0.43)$ & $4.14(0.77)$ & $1.79(1.06)$ \\
\hline
\end{tabular}

Abbreviations: BPI, Brief Pain Inventory; HADS, Hospital Anxiety and Depression Scale; SETS, Stanford Expectations of Treatment Scales.

Table 3 Group Means and Standard Deviations on the Primary, Secondary, and Exploratory Treatment Outcomes (Raw Scores)

\begin{tabular}{|l|l|l|l|l|}
\hline & Baseline & Placebo & DXM & End Baseline \\
\hline Generalized Pain & $55.30(17.46)$ & $45.55(24.69)$ & $41.09(24.32)$ & $44.90(26.23)$ \\
Physical Activity & $52.56(17.87)$ & $50.10(19.70)$ & $46.92(19.79)$ & $45.32(22.07)$ \\
Highest Pain & $62.26(19.06)$ & $50.94(27.06)$ & $45.26(26.24)$ & $49.05(27.87)$ \\
Muscle Pain & $55.30(20.55)$ & $44.12(26.42)$ & $40.11(25.74)$ & $42.31(28.61)$ \\
Fatigue & $67.52(10.95)$ & $51.69(16.89)$ & $45.92(21.88)$ & $50.56(23.88)$ \\
Depression & $26.67(16.66)$ & $21.40(18.07)$ & $20.95(20.00)$ & $24.05(21.74$ \\
\hline
\end{tabular}

Note: Averages were calculated over the entire treatment period.

Abbreviation: $\mathrm{Gl}$, gastrointestinal.

The secondary outcome of physical activity was 50.1 in the placebo condition and 46.9 in the DXM condition. The GEE showed no significant difference between the conditions $(b=-3.715, p=0.181)$.

\section{Exploratory Analyses}

Exploratory analyses assessed the primary and secondary outcomes, as well as additional outcomes, for the entire placebo and treatment periods, rather than the final four 


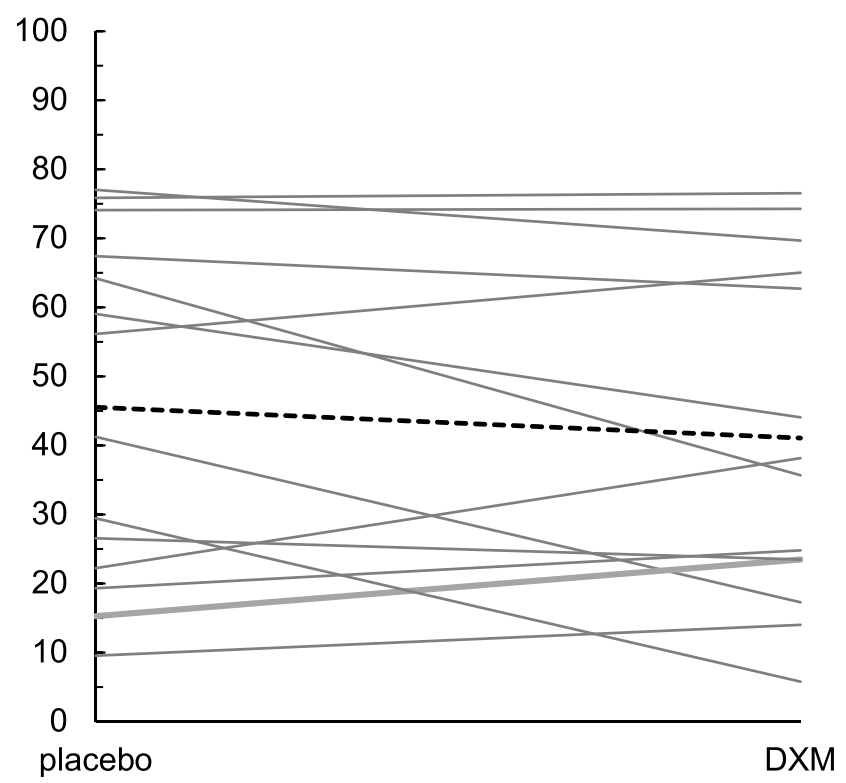

Figure 2 Individual changes in generalized pain ratings between the placebo and DXM conditions. The bold dashed line represents the change from mean placebo and mean DXM scores across participants.

weeks. These models tested: generalized pain, physical activity, muscle pain, highest pain, fatigue, and depressed mood. The models used the same GEE procedure as in the tests of the main treatment effects, but also included time (measured in days in the study) and the time-by-condition interaction. These additional terms were used to test for differences in the rate of change in outcome severity between conditions.

The results of the analyses are shown in Table 4 . When using the entire placebo and DXM condition, the difference in generalized pain was significant $(b=-9.933$, $p=0.013)$. The time-by-condition interaction was significant ( $b=0.241, p=0.002$ ), whereby the trend of pain ratings over time was -0.251 in the placebo condition and -0.010 , ie flatter, in the DXM condition. Entering demographic variables (age, FM duration) into the model revealed no significant effect of either variable (age: $b=$ $-0.197, p=0.281$; FM duration: $b=-0.143, p=0.588$ ), or their interactions with the treatment effect (age*condition: $b=0.324, \quad p=0.236 ; \quad \mathrm{FM}$ duration*condition: $b=0.211, p=0.607)$. There was no unique effect of compliance with daily study medication on generalized pain scores $(b=0.925, p=0.254)$, and no interaction between medication compliance and the treatment condition $(b=$ $-0.832, p=0.758)$, meaning that day-to-day variability in treatment compliance did not predict generalized pain above the general DXM treatment effect.
Model estimates for physical activity, muscle pain, highest pain, fatigue, and depressed mood are also seen in Table 4. No effects for condition were generally seen for the outcomes. The greatest exception was the highest pain, which was significantly lower in the DXM condition $(b=-9.657, p=0.016)$, indicating that DXM may work by ameliorating more severe pain. The day*condition interaction was also significant, indicating that the negative trend over time during the placebo condition $(b=-0.264, p<0.001)$ was flattened during DXM treatment (day*condition: $b=0.236, p=0.002$; slope $=-0.028$ ).

\section{Adverse Events}

A list of reported adverse events can be found in Table 5 . The most frequently observed adverse event was elevated

Table 4 GEE Model Estimates from Sensitivity Analyses Predicting Study Outcomes Over the Entire Treatment Period

\begin{tabular}{|c|c|c|c|c|}
\hline Parameters & Estimate (b) & SE & $\mathbf{Z}$ & $p$ \\
\hline \multicolumn{5}{|l|}{ Generalized Pain } \\
\hline Intercept & 9.009 & 3.323 & 2.71 & 0.007 \\
\hline Day & -0.251 & 0.087 & -2.89 & 0.004 \\
\hline Condition (DXM) & -9.933 & 3.987 & -2.49 & 0.013 \\
\hline Day*Condition & $0.24 I$ & 0.079 & 3.04 & 0.002 \\
\hline \multicolumn{5}{|l|}{ Physical Activity } \\
\hline Intercept & 4.221 & 2.171 & 1.940 & 0.052 \\
\hline Day & -0.071 & 0.048 & -1.47 & 0.142 \\
\hline Condition (DXM) & -3.732 & 3.131 & -1.19 & 0.233 \\
\hline Day*Condition & 0.045 & 0.061 & 0.75 & 0.456 \\
\hline \multicolumn{5}{|l|}{ Muscle Pain } \\
\hline Intercept & 8.294 & 3.390 & 2.45 & 0.014 \\
\hline Day & -0.244 & 0.094 & -2.59 & 0.010 \\
\hline Condition (DXM) & -6.738 & 4.789 & -1.41 & 0.159 \\
\hline Day*Condition & 0.208 & 0.094 & 2.21 & 0.027 \\
\hline \multicolumn{5}{|l|}{ Highest Pain } \\
\hline Intercept & 9.768 & 2.996 & 3.26 & 0.001 \\
\hline Day & -0.264 & 0.077 & -3.41 & $<0.001$ \\
\hline Condition (DXM) & -9.657 & 4.012 & -2.41 & 0.016 \\
\hline Day*Condition & 0.236 & 0.075 & 3.17 & 0.002 \\
\hline \multicolumn{5}{|l|}{ Fatigue } \\
\hline Intercept & 8.019 & 4.216 & 1.90 & 0.057 \\
\hline Day & -0.177 & 0.104 & -1.70 & 0.088 \\
\hline Condition (DXM) & -5.383 & 5.244 & -1.03 & 0.305 \\
\hline Day*Condition & 0.114 & 0.092 & 1.25 & 0.213 \\
\hline \multicolumn{5}{|l|}{ Depression } \\
\hline Intercept & 2.937 & 1.651 & 1.78 & 0.075 \\
\hline Day & -0.101 & 0.052 & -1.94 & 0.053 \\
\hline Condition (DXM) & -5.322 & 2.789 & -1.91 & 0.056 \\
\hline Day*Condition & 0.132 & 0.070 & 1.88 & 0.060 \\
\hline
\end{tabular}

Abbreviation: SE, standard error. 
Table 5 Adverse Event Occurrences During Placebo and DXM Treatment

\begin{tabular}{|l|l|l|}
\hline Event & Placebo & DXM \\
\hline Anxiety & - & 002,010 \\
Bloating & 004 & 004 \\
Chest Tightness & - & 002 \\
Cold/Respiratory Infection & 012 & - \\
Constipation & - & 002,004 \\
Depressed Mood & 003 & 002 \\
Diarrhea & - & 002,004 \\
Ear Infection & 011 & - \\
Elevated Alk Phosphatase & - & 004,005 \\
Elevated ALT & - & $001,004,007$ \\
Elevated Chloride & - & 005 \\
Eye Redness & - & 014 \\
Fever & 009 & - \\
Gallbladder Dysfunction & - & 005 \\
Gastrointestinal Upset & 002 & 002,009 \\
Hot Flashes & - & 006,010 \\
Low Alk Phosphatase & 012 & - \\
Low ALT & - & 014 \\
Low AST & 012 & 012 \\
Muscle Weakness & 004 & - \\
Nausea & - & 004,013 \\
Rash & 010 & - \\
Sore Throat & - & 009 \\
Vomiting & - & 004,013 \\
\hline Abbrevations: ALT, & - & - \\
\hline
\end{tabular}

Abbreviations: ALT, alanine aminotransferase; ESR, erythrocyte sedimentation rate; HCG, human chorionic gonadotropin; HS CRP, high-sensitivity C-reactive protein; TSH, thyroid-stimulating hormone.

alanine aminotransferase, observed in three participants. Adverse events seen in at least two participants in the DXM condition included anxiety, constipation, diarrhea, elevated alkaline phosphatase, gastrointestinal upset, hot flashes, nausea, and vomiting. No serious adverse events requiring hospitalization or treatment occurred during the study.

\section{Discussion}

This study tested the effectiveness of low-dose DXM for improving pain and other symptoms in FM. Fourteen women with FM received placebo and DXM over 15 weeks in a single-blind trial. When contrasting the final four weeks of the placebo and DXM periods, no significant differences were found in the primary outcome of general body pain, or the secondary outcome of physical activity, meaning that the primary study hypotheses were not supported. In exploratory analyses over the entire treatment period, both general pain and maximum pain were significantly lower in the DXM condition. Pain was reduced by $30 \%$ from baseline levels, which is typical for chronic pain treatments. The lack of significant results when analyzing the last four weeks of treatment could be a result of reduced statistical power, but also could mean that DXM effects are more pronounced in the beginning of treatment. It should be noted that placebo effects usually contribute to the overall benefits of a drug, evidenced in the current study by changes in all major outcomes when comparing the placebo period to baseline scores (see Table 3). In order to determine whether the placebo effects are mediated by physiological (eg antiinflammatory) or psychological (eg expectancy) effects, or a combination of both, future studies could measure these variables directly, for example, via serum inflammatory markers and validated drug expectancy questionnaires.

Few side effects were reported in the current study. We do note ALT elevations during DXM treatment that were absent during the placebo phase. While reported previously, ${ }^{58}$ such elevations were not expected given the low dosage used, and suggest that DXM can increase demands on liver metabolism for some individuals. Future trials of DXM, at any dosage, should closely monitor ALT and other liver enzymes.

There are two potential mechanisms for DXM. Classically, DXM is thought to reduce pain via antagonist actions on NMDA receptors, consistent with the central sensitization hypothesis. ${ }^{3-7,59-61}$ Several early animal studies demonstrated that NMDA-receptor antagonism abolishes hyperalgesia ${ }^{62-64}$ and NMDA antagonists such as ketamine and memantine have already been shown to reduce FM pain in humans. ${ }^{65-69}$ We focus here on an alternative explanation for DXM's analgesic effects, namely the mediation of inflammatory processes in the brain. DXM has been shown to suppress microglial excitability in vivo, with neuroprotective benefits. ${ }^{42}$ These actions are exerted partially through its active metabolite, 3-hydroxymorphinan. ${ }^{44}$ Reducing microglia excitability may be relevant in FM given recent neuroimaging data demonstrating abnormally high microglial activation in the disease. ${ }^{24}$ To conclusively determine the mechanism of action leading to DXM's analgesic effects, future studies could analyze peripheral or central inflammation markers, and would ideally incorporate neuroimaging correlates of inflammation, such as Magnetic Resonance Spectroscopy or PET imaging. 


\section{Limitations}

There are several limitations to this study. First, the medication was tested in a small number of FM patients, which limits generalizability to a wider population and prevented subgroup analyses. For example, a prior trial found that intravenous ketamine predicted the subsequent response to oral DXM in FM patients, suggesting the presence of important subgroups we could not investigate here. ${ }^{45}$ Second, we did not conduct dose-finding analyses, and it is possible that larger dosages, or more frequent dosings, would have yielded superior pain relief. Third, the durability of DXM responses is unknown, as participants took the treatment for only 10 weeks. This has important implications for clinical management, as chronic pain conditions such as FM would require a treatment with durable effects. Fourth, our single-blind design could have led to experimenter bias. While we found that blinding was effective, future studies could further minimize such problems by utilizing double-blind designs and randomization to treatment conditions. Fifth, we did not utilize objective pain assessments such as pain threshold testing, which should be incorporated in future trials.

\section{Conclusions}

In this pilot study, we did not find strong evidence to support DXM as an important treatment for FM. Future studies exploring DXM as a treatment for chronic pain may consider different dosages and dosing schedules. This study does not change guidance to clinicians on treating FM. Experimental medications, including DXM, should not be used as a first-line treatment due to the limited amount of evidence that currently supports their use in these populations. Considerably more research would need to be conducted before DXM can be considered as a viable FM treatment option.

\section{Abbreviations}

ACR, American College of Rheumatology; ALT, alanine transaminase; BPI, Brief Pain Inventory; DAST-10, Drug Abuse Screening Test (10-item version); DXM, dextromethorphan; FDA, Food and Drug Administration; FM, fibromyalgia; GEE, generalized estimating equations; HADS, Hospital Anxiety and Depression Scale; IL, interleukin; NMDA, N-methyl-D-aspartic acid; PET, positron emission tomography; PGIC, Patient Global Impressions of Change; SETS, Stanford Expectations of Treatment Scale; SSS, Symptom Severity Scale; TLR-4, toll-like receptor 4; TNF, tumor necrosis factor; TSPO, translocator protein; UAB, University of Alabama at Birmingham; WPI, Widespread Pain Index.

\section{Data Sharing Statement}

Data are not publicly available as consent to share was not obtained from participants.

\section{Acknowledgments}

We would like to thank Alexis Lambert for assistance with data collection.

\section{Author Contributions}

All authors contributed to data analysis, drafting or revising the article, have agreed on the journal to which the article will be submitted, gave final approval of the version to be published, and agree to be accountable for all aspects of the work.

\section{Funding}

The study was supported by the Psychology Department of the University of Alabama at Birmingham.

\section{Disclosure}

The authors declare no conflicts of interest for this work.

\section{References}

1. Wolfe F, Clauw DJ, Fitzcharles MA, et al. 2016 Revisions to the 2010/ 2011 fibromyalgia diagnostic criteria. Semin Arthritis Rheum. 2016;46 (3):319-329. doi:10.1016/j.semarthrit.2016.08.012

2. Wolfe F, Clauw DJ, Fitzcharles M-A, et al. The American College of Rheumatology preliminary diagnostic criteria for fibromyalgia and measurement of symptom severity. Arthritis Care Res (Hoboken). 2010;62(5):600-610. doi:10.1002/acr.20140

3. Staud R, Cannon RC, Mauderli AP, Robinson ME, Price DD, Vierck CJ. Temporal summation of pain from mechanical stimulation of muscle tissue in normal controls and subjects with fibromyalgia syndrome. Pain. 2003;102(1-2):87-95. doi:10.1016/s0304-3959(02)00344-5

4. Staud R, Craggs JG, Perlstein WM, Robinson ME, Price DD. Brain activity associated with slow temporal summation of C-fiber evoked pain in fibromyalgia patients and healthy controls. Eur J Pain. 2008;12 (8):1078-1089. doi:10.1016/j.ejpain.2008.02.002

5. Staud R, Robinson ME, Price DD. Temporal summation of second pain and its maintenance are useful for characterizing widespread central sensitization of fibromyalgia patients. $J$ Pain. 2007;8 (11):893-901. doi:10.1016/j.jpain.2007.06.006

6. Staud R, Vierck CJ, Cannon RL, Mauderli AP, Price DD. Abnormal sensitization and temporal summation of second pain (wind-up) in patients with fibromyalgia syndrome. Pain. 2001;91(1-2):165-175. doi:10.1016/S0304-3959(00)00432-2

7. Staud R, Weyl EE, Riley JL, Fillingim RB. Slow temporal summation of pain for assessment of central pain sensitivity and clinical pain of fibromyalgia patients. PLoS One. 2014;9(2):e89086. doi:10.1371/journal.pone.0089086

8. Cagnie B, Coppieters I, Denecker S, Six J, Danneels L, Meeus M. Central sensitization in fibromyalgia? A systematic review on structural and functional brain MRI. Semin Arthritis Rheum. 2014;44 (1):68-75. doi:10.1016/j.semarthrit.2014.01.001

9. Lund I, Lundeberg T, Carleson J, Sönnerfors H, Uhrlin B, Svensson E. Corticotropin releasing factor in urine-a possible biochemical marker of fibromyalgia. Responses to massage and guided relaxation. Neurosci Lett. 2006;403(1-2):166-171. doi:10.1016/j.neulet.2006.04.038 
10. McLean SA, Williams DA, Stein PK, et al. Cerebrospinal fluid corticotropin-releasing factor concentration is associated with pain but not fatigue symptoms in patients with fibromyalgia. Neuropsychopharmacology. 2006;31(12):2776-2782. doi:10.1038/sj.npp.1301200

11. Becker S, Schweinhardt P. Dysfunctional neurotransmitter systems in fibromyalgia, their role in central stress circuitry and pharmacological actions on these systems. Pain Res Treat. 2012;2012:741746. doi: $10.1155 / 2012 / 741746$

12. Stahl SM. Fibromyalgia-pathways and neurotransmitters. Hum Psychopharmacol. 2009;24(Suppl 1):S11-17. doi:10.1002/hup.1029

13. Harris RE. Elevated excitatory neurotransmitter levels in the fibromyalgia brain. Arthritis Res Ther. 2010;12(5):141. doi:10.1186/ ar3136

14. Russell IJ, Orr MD, Littman B, et al. Elevated cerebrospinal fluid levels of substance P in patients with the fibromyalgia syndrome. Arthritis Rheum. 1994;37(11):1593-1601. doi:10.1002/art.1780371106

15. Bidari A, Ghavidel-Parsa B, Rajabi S, Sanaei O, Toutounchi M. The acute effect of maximal exercise on plasma beta-endorphin levels in fibromyalgia patients. Korean J Pain. 2016;29(4):249-254. doi:10.3344/kjp.2016.29.4.249

16. Cording M, Derry S, Phillips T, Moore RA, Wiffen PJ. Milnacipran for pain in fibromyalgia in adults. Cochrane Database Syst Rev. 2015;2015(10):Cd008244.

17. Arnold LM, Hess EV, Hudson JI, Welge JA, Berno SE, Keck PE. A randomized, placebo-controlled, double-blind, flexible-dose study of fluoxetine in the treatment of women with fibromyalgia. Am J Med. 2002;112(3):191-197. doi:10.1016/S0002-9343(01)01089-0

18. Walitt B, Urrútia G, Nishishinya MB, Cantrell SE, Häuser W. Selective serotonin reuptake inhibitors for fibromyalgia syndrome. Cochrane Database Syst Rev. 2015;2015(6):Cd011735.

19. Harris RE, Clauw DJ, Scott DJ, McLean SA, Gracely RH, Zubieta JK. Decreased central mu-opioid receptor availability in fibromyalgia. J Neurosci. 2007;27(37):10000-10006. doi:10.1523/ JNEUROSCI.2849-07.2007

20. Rao SG, Clauw DJ. The management of fibromyalgia. Drugs Today. 2004;40(6):539-554. doi:10.1358/dot.2004.40.6.850485

21. Goldenberg DL, Clauw DJ, Palmer RE, Clair AG. Opioid use in fibromyalgia: a cautionary tale. Mayo Clin Proc. 2016;91 (5):640-648. doi:10.1016/j.mayocp.2016.02.002

22. Fitzcharles M-A, Faregh N, Ste-Marie PA, Shir Y. Opioid use in fibromyalgia is associated with negative health related measures in a prospective cohort study. Pain Res Treat. 2013;2013:898493. doi: $10.1155 / 2013 / 898493$

23. Peng X, Robinson RL, Mease P, et al. Long-term evaluation of opioid treatment in fibromyalgia. Clin $J$ Pain. 2015;31(1):7-13. doi:10.1097/AJP.0000000000000079

24. Albrecht DS, Forsberg A, Sandström A, et al. Brain glial activation in fibromyalgia - a multi-site positron emission tomography investigation. Brain Behav Immun. 2019;75:72-83. doi:10.1016/j. bbi.2018.09.018

25. Davalos D, Grutzendler J, Yang G, et al. ATP mediates rapid microglial response to local brain injury in vivo. Nat Neurosci. 2005;8 (6):752-758. doi:10.1038/nn1472

26. Ransohoff RM, Perry VH. Microglial physiology: unique stimuli, specialized responses. Annu Rev Immunol. 2009;27:119-145. doi:10.1146/annurev.immunol.021908.132528

27. D'Ambrosi N, Finocchi P, Apolloni S, et al. The proinflammatory action of microglial P2 receptors is enhanced in SOD1 models for amyotrophic lateral sclerosis. J Immunol. 2009;183(7):4648-4656. doi:10.4049/jimmunol.0901212

28. Lynch MA. The multifaceted profile of activated microglia. Mol Neurobiol. 2009;40(2):139-156.

29. Sharma M, Arbabzada N, Flood PM. Mechanism underlying beta2-AR agonist-mediated phenotypic conversion of LPS-activated microglial cells. J Neuroimmunol. 2019;332:37-48. doi:10.1016/j. jneuroim.2019.03.017
30. Bianchi M, Sacerdote P, Ricciardi-Castagnoli P, Mantegazza P, Panerai AE. Central effects of tumor necrosis factor alpha and interleukin-1 alpha on nociceptive thresholds and spontaneous locomotor activity. Neurosci Lett. 1992;148(1-2):76-80. doi:10.1016/ 0304-3940(92)90808-K

31. Aaron LA, Burke MM, Buchwald D. Overlapping conditions among patients with chronic fatigue syndrome, fibromyalgia, and temporomandibular disorder. Arch Intern Med. 2000;160(2):221-227. doi:10.1001/archinte.160.2.221

32. Dantzer R. Cytokine-induced sickness behavior: mechanisms and implications. Ann N Y Acad Sci. 2001;933:222-234. doi:10.1111/ j.1749-6632.2001.tb05827.x

33. Dantzer R. Cytokine-induced sickness behaviour: a neuroimmune response to activation of innate immunity. Eur $J$ Pharmacol. 2004;500(1-3):399-411. doi:10.1016/j.ejphar.2004.07.040

34. Dantzer R, Bluthe RM, Gheusi G, et al. Molecular basis of sickness behavior. Ann N Y Acad Sci. 1998;856:132-138. doi:10.1111/j.17496632.1998.tb08321.x

35. Poon DC, Ho YS, Chiu K, Wong HL, Chang RC. Sickness: from the focus on cytokines, prostaglandins, and complement factors to the perspectives of neurons. Neurosci Biobehav Rev. 2015;57:30-45. doi:10.1016/j.neubiorev.2015.07.015

36. Patten DK, Schultz BG, Berlau DJ. The safety and efficacy of lowdose naltrexone in the management of chronic pain and inflammation in multiple sclerosis, fibromyalgia, Crohn's disease, and other chronic pain disorders. Pharmacotherapy. 2018;38(3):382-389. doi:10.1002/ phar.2086

37. Younger J, Mackey S. Fibromyalgia symptoms are reduced by low-dose naltrexone: a pilot study. Pain Medicine. 2009;10 (4):663-672. doi:10.1111/j.1526-4637.2009.00613.x

38. Parkitny L, Younger J. Reduced pro-inflammatory cytokines after eight weeks of low-dose naltrexone for fibromyalgia. Biomedicines. 2017;5:2. doi:10.3390/biomedicines5020016

39. Cheng W, Li Y, Hou X, et al. Determining the neuroprotective effects of dextromethorphan in lipopolysaccharidestimulated BV2 microglia. Mol Med Rep. 2015;11(2):1132-1138. doi:10.3892/mmr.2014.2794

40. Lee J-H, Choi S-H, Shin T-J, et al. Effect of dextromethorphan on human Kv1.3 channel activity: involvement of C-type inactivation. Eur J Pharmacol. 2011;651(1):122-127. doi:10.1016/j.ejphar.20 10.10.091

41. Li G, Cui G, Tzeng N-S, et al. Femtomolar concentrations of dextromethorphan protect mesencephalic dopaminergic neurons from inflammatory damage. FASEB J. 2005;19(6):489-496. doi:10.1096/ fj.04-2555com

42. Liu Y, Qin L, Li G, et al. Dextromethorphan protects dopaminergic neurons against inflammation-mediated degeneration through inhibition of microglial activation. J Pharmacol Exp Ther. 2003;305 (1):212-218. doi:10.1124/jpet.102.043166

43. Song J-H, Yeh JZ. Dextromethorphan inhibition of voltage-gated proton currents in BV2 microglial cells. Neurosci Lett. 2012;516 (1):94-98. doi:10.1016/j.neulet.2012.03.065

44. Zhang W, Qin L, Wang T, et al. 3-hydroxymorphinan is neurotrophic to dopaminergic neurons and is also neuroprotective against LPS-induced neurotoxicity. FASEB J. 2005;19(3):395-397. doi:10.1096/fj.04-1586fje

45. Cohen SP, Verdolin MH, Chang AS, Kurihara C, Morlando BJ, Mao J. The intravenous ketamine test predicts subsequent response to an oral dextromethorphan treatment regimen in fibromyalgia patients. J Pain. 2006;7(6):391-398. doi:10.1016/j.jpain.2005.12.010

46. Journey JD, Stern E. Dextromethorphan Toxicity. Treasure Island (FL): StatPearls Publishing; 2019.

47. Chechneva OV, Mayrhofer F, Daugherty DJ, Pleasure DE, Hong JS, Deng W. Low dose dextromethorphan attenuates moderate experimental autoimmune encephalomyelitis by inhibiting NOX2 and reducing peripheral immune cells infiltration in the spinal cord. Neurobiol Dis. 2011;44(1):63-72. doi:10.1016/j.nbd.2011.06.004 
48. Busner J, Targum SD. The clinical global impressions scale: applying a research tool in clinical practice. Psychiatry. 2007;4(7):28-37.

49. Cleeland CS, Ryan KM. Pain assessment: global use of the Brief Pain Inventory. Ann Acad Med Singapore. 1994;23(2):129-138.

50. Stern AF. The Hospital anxiety and depression scale. Occup Med (Chic Ill). 2014;64(5):393-394. doi:10.1093/occmed/kqu024

51. Younger J, Gandhi V, Hubbard E, Mackey S. Development of the Stanford Expectations of Treatment Scale (SETS): a tool for measuring patient outcome expectancy in clinical trials. Clin Trials. 2012;9 (6):767-776. doi:10.1177/1740774512465064

52. Skinner HA. Drug Use Questionnaire (DAST-20). Addiction Research Foundation; 1982.

53. Barnhart JW, Massad EN. Determination of dextromethorphan in serum by gas chromatography. $J$ Chromatogr. 1979;163 (4):390-395. doi:10.1016/S0378-4347(00)81642-4

54. Marier JF, Deschenes JL, Hage A, et al. Enhancing the uptake of dextromethorphan in the CNS of rats by concomitant administration of the P-gp inhibitor verapamil. Life Sci. 2005;77(23):2911-2926. doi:10.1016/j.1fs.2005.04.025

55. Perry PJ, Fredriksen K, Chew S, et al. The effects of dextromethorphan on driving performance and the standardized field sobriety test. J Forensic Sci. 2015;60(5):1258-1262. doi:10.1111/1556-4029.12833

56. Carter LP, Reissig CJ, Johnson MW, Klinedinst MA, Griffiths RR, Mintzer MZ. Acute cognitive effects of high doses of dextromethorphan relative to triazolam in humans. Drug Alcohol Depend. 2013;128(3):206-213. doi:10.1016/j.drugalcdep.2012.08.025

57. Reissig CJ, Carter LP, Johnson MW, Mintzer MZ, Klinedinst MA, Griffiths RR. High doses of dextromethorphan, an NMDA antagonist, produce effects similar to classic hallucinogens. Psychopharmacology. 2012;223(1):1-15. doi:10.1007/s00213-012-2680-6

58. Pope LE, Schoedel KA, Bartlett C, Sellers EM. A study of potential pharmacokinetic and pharmacodynamic interactions between dextromethorphan/quinidine and memantine in healthy volunteers. Clin Drug Investig. 2012;32(8):e1-15. doi:10.1007/BF03261905

59. de la Coba P, Bruehl S, Moreno-Padilla M, Reyes Del Paso GA. Responses to slowly repeated evoked pain stimuli in fibromyalgia patients: evidence of enhanced pain sensitization. Pain Medicine. 2017;18(9):1778-1786. doi:10.1093/pm/pnw361

60. O’Brien AT, Deitos A, Trinanes Pego Y, Fregni F, Carrillo-de-laPena MT. Defective endogenous pain modulation in fibromyalgia: a meta-analysis of temporal summation and conditioned pain modulation paradigms. J Pain. 2018;19(8):819-836. doi:10.1016/j. jpain.2018.01.010
61. Price DD, Staud R, Robinson ME, Mauderli AP, Cannon R, Vierck CJ. Enhanced temporal summation of second pain and its central modulation in fibromyalgia patients. Pain. 2002;99(1-2):49-59. doi:10.1016/S0304-3959(02)00053-2

62. Davies SN, Lodge D. Evidence for involvement of N-methylaspartate receptors in 'wind-up' of class 2 neurones in the dorsal horn of the rat. Brain Res. 1987;424(2):402-406. doi:10.1016/0006-8993(87) 91487-9

63. Dickenson AH, Sullivan AF. Evidence for a role of the NMDA receptor in the frequency dependent potentiation of deep rat dorsal horn nociceptive neurones following $\mathrm{C}$ fibre stimulation. Neuropharmacology. 1987;26(8):1235-1238. doi:10.1016/00283908(87)90275-9

64. Parada CA, Luccarini P, Woda A. Effect of an NMDA receptor antagonist on the wind-up of neurons in the trigeminal oralis subnucleus. Brain Res. 1997;761(2):313-320. doi:10.1016/S00068993(97)00355-7

65. Fayed N, Olivan-Blazquez B, Herrera-Mercadal P, et al. Changes in metabolites after treatment with memantine in fibromyalgia. A double-blind randomized controlled trial with magnetic resonance spectroscopy with a 6-month follow-up. CNS Neurosci Ther. 2014;20(11):999-1007. doi:10.1111/cns.12314

66. Graven-Nielsen T, Aspegren Kendall S, Henriksson KG, et al. Ketamine reduces muscle pain, temporal summation, and referred pain in fibromyalgia patients. Pain. 2000;85(3):483-491. doi:10.1016/S0304-3959(99)00308-5

67. Noppers I, Niesters M, Swartjes M, et al. Absence of long-term analgesic effect from a short-term S-ketamine infusion on fibromyalgia pain: a randomized, prospective, double blind, active placebo-controlled trial. Eur J Pain. 2011;15(9):942-949. doi:10.1016/j.ejpain.2011.03.008

68. Olivan-Blazquez B, Herrera-Mercadal P, Puebla-Guedea M, et al. Efficacy of memantine in the treatment of fibromyalgia: a double-blind, randomised, controlled trial with 6-month follow-up. Pain. 2014;155(12):2517-2525. doi:10.1016/j.pain.2014.09.004

69. Sorensen J, Bengtsson A, Backman E, Henriksson KG, Bengtsson M. Pain analysis in patients with fibromyalgia. Effects of intravenous morphine, lidocaine, and ketamine. Scand J Rheumatol. 1995;24 (6):360-365. doi:10.3109/03009749509095181
Journal of Pain Research

\section{Publish your work in this journal}

The Journal of Pain Research is an international, peer reviewed, open access, online journal that welcomes laboratory and clinical findings in the fields of pain research and the prevention and management of pain. Original research, reviews, symposium reports, hypothesis formation and commentaries are all considered for publication. The manuscript management system is completely online and includes a very quick and fair peer-review system, which is all easy to use. Visit http:// www.dovepress.com/testimonials.php to read real quotes from published authors. 